\title{
Produção CERÂMiCA NO InÍCIO do NeOlítico EM Portugal: DAdOS ReCENTES SOBRE OS VI E V MILÉNIOS A.C.
}

Pottery Production at the Beginning of the Neolithic in Portugal: Recent Data on the $6^{\text {th }}$ and $5^{\text {th }}$ Millennia BC

\section{ANTÓNIO FAUSTINO CARVALHO (D)}

CEAACP - Centro de Estudios de Arqueologia, arte e Ciências do Patrimonio. Universidade do Algarve. afcarva@ualg.pt

\section{Resumo:}

Uma caracterização das primeiras cerâmicas neolíticas de Portugal (VI milénio a.C.) foi há poucos anos publicada nas páginas desta mesma revista. No entanto, a investigação mais recente tem vindo a dar atenção a três aspetos, que são discutidos aqui: 1) a relação entre cerâmica cardial e boquique, em que a primeira se pode considerar mais antiga se se atender a uma avaliação crítica da evidência cronoestratigráfica disponível; 2) os novos achados da chamada "cerâmica simbólica", que incluem abundante evidência de representações antropomórficas e zoomórficas a par de exemplos, mais escassos, de plantas e representações solares; e 3) as análises petrográficas e químicas de cerâmica e argilas, que apontam para a conclusão segundo a qual peças cardiais e com cordões eram transportadas a longa distância por via marítima. Alguns sítios atualmente em estudo poderão proporcionar novos conhecimentos sobre estes temas num futuro próximo.

Palavras chave: Neolítico, Portugal, cardial, boquique, "cerâmica simbólica”.

\section{Abstract:}

A characterisation of the earliest pottery productions in Neolithic Portugal (6th millennium BC) was published in the pages of this journal a few years ago. However, three aspects have been receiving further attention by current research and are discussed here: 1) the relation between Cardial and Boquique-decorated potteries, in which the former are clearly more ancient if a critical evaluation of the available chrono-stratigraphic evidence is carried out;2) new finds of so-called "symbolic pottery", which includes abundant evidence for anthropomorphic and zoomorphic depictions along with more scarce examples of plant and solar representations; and 3) petrographic and chemical analyses of ceramics and clays, both pointing to the conclusion that Cardial and corded pots were being transported through longdistance, maritime travels. Some sites currently under analyses may provide in the near future new insights into those research topics.

Key words: Neolithic, Portugal, Cardial, "Boquique”, "symbolic pottery”. 


\section{INTRODUÇÃO}

Uma obra coletiva, dada à estampa no volume Extra n. 12 desta mesma revista, incluiu um capítulo onde se apresenta uma síntese das produções cerâmicas do primeiro Neolítico do atual território português, isto é, da segunda metade do VI milénio a.C. (Carvalho 2011). Nesse texto tratou-se, sucessivamente, de três aspetos: em primeiro lugar, do inventário descritivo dos sítios datados ou atribuíveis a essa fase (incluindo os diversos achados de vasos isolados que se conhecem no país); de seguida, dos traços gerais que caracterizam, do ponto de vista morfológico e decorativo, essas produções; e, finalmente, da discussão em torno da sua integração cronológica e cultural no processo de neolitização do S de Portugal. Em cartela constam ainda estudos específicos sobre dois sítios daquele milénio - a Galeria da Cisterna da Gruta do Almonda (Zilhão e Carvalho 2011) e o Carrascal (Cardoso 2011) - e de um outro, datado da transição do VI para o V milénio, a Valada do Mato (Diniz 2011).

Desde então poucos dados novos se poderão adicionar ao panorama descrito para o VI milénio. Com exceção dos interessantes contextos de Casas Novas (Gonçalves e Sousa 2014) e da designada Baixa do Xerez (Gonçalves et al. 2013), respetivamente na margem esquerda do Baixo Tejo e no Guadiana português, nenhum outro foi até ao momento objeto de publicação com descrição da sua componente cerâmica. Para uma imagem mais completa das produções cerâmicas deste milénio será necessário aguardar pelos respetivos estudos do recinto de fossos cardial de Senhora da Alegria (Valera 2013), no Vale do Mondego, e dos sítios de ar livre de Cerradinho do Ginete (Carvalho 2008; 2011), na Serra d'Aire, Lapiás das Lameiras (Davis e Simões 2016), na "península de Lisboa", e Vale Pincel (Silva e Soares 2015), no litoral alentejano.

Portanto, só futuramente se poderá voltar a esboçar um outro quadro, mais abrangente, das produções cerâmicas do VI milénio a.C. Esse quadro deverá então proporcionar um entendimento mais fundamentado, entre outros, de dois temas em particular: o porquê da quase inexistência de cerâmica cardial na "península de Lisboa" em contextos datados de ca. 5500-5200 cal BC (ou seja, contemporâneos dos cardiais do centro e $\mathrm{N}$ da região estremenha) e procurar sistematizar os dados estilísticos e contextuais das produções cerâmicas que se têm vindo a encontrar em (suposto) ambiente mesolítico no Alentejo. Neste último caso, trata-se em particular dos concheiros do vale do rio Sado, que se encontram envoltos em diversas incógnitas e têm proporcionando interpretações díspares, ou pelo menos não totalmente concordantes entre si. Por exemplo, numa reanálise do concheiro de Amoreiras, Diniz (2010: 53) considera que a presença de materiais cerâmicos do Neolítico antigo, do Neolítico final e do período romano nas camadas 2 e 3 de Heleno [o primeiro escavador do sítio], portanto entre os 25 e os 75 $\mathrm{cm}$ de profundidade, demonstra como a escavação por camadas artificiais é, num sítio que apresenta uma estratigrafia horizontal muito diferenciada, um instrumento de controlo das realidades de terreno, não apenas inútil como enganador, e conclui interrogando-se se os materiais do Neolítico antigo encontrados neste concheiro não traduzirão ocupações posteriores de um espaço com uma longa diacronia de ocupação. Numa perspetiva geral sobre o mesmo vale, Soares (2013) considera, ao invés, haver dados contextuais e cronométricos seguros que apontam para que a cerâmica tenha de facto sido adotada pelas populações mesolíticas a partir de finais do VI milénio a.C., através de contactos com grupos neolíticos instalados na costa SO portuguesa.

Perante o exposto, o texto que se segue - que deve ser entendido como um complemento daquele a que se tem vindo a fazer referência (Carvalho 2011) - irá abordar os seguintes temas, restritos ao S português (regiões da Estremadura, Alentejo e Algarve):

1. A evidência cronostratigráfica disponível para a relação entre cerâmica cardial e cerâmica boquique e os processos culturais que daí se podem inferir;

2. As ocorrências de "cerâmica simbólica" no Neolítico antigo, parte das quais apenas muito recentemente (re)identificada; e

3. Os resultados obtidos num projeto de análises petrográficas e químicas de vários conjuntos cerâmicos neolíticos antigos do Maciço Calcário Estremenho e do ocidente algarvio.

\section{CARDIAL E BOQUIQUE: UMA RELAÇÃO NA DIACRONIA}

A análise da dispersão geográfica e cronologias específicas das produções cerâmicas de tipo cardial e boquique (estas últimas, por vezes, também apelidadas por vários autores como punto y raya) tem levantado muitas possibilidades interpretativas, designadamente acerca do processo de neolitização de que ambas parecem poder ser 
testemunho. $\mathrm{O}$ atual território português é importante no âmbito desta questão porque são as regiões lusas e a Extremadura Espanhola as que reúnem a larga maioria de ocorrências em toda a península (cf. Alday et al. 2009: mapa 1). Nesse sentido, abstraindo-nos de aspetos morfológicos e estilísticos específicos, cuja discussão remete para um patamar distinto de análise, torna-se pertinente escrutinar os dados portugueses em maior detalhe.

Num primeiro trabalho de amplo fôlego, foi possível fazer uma caracterização sistemática desta técnica à escala da península Ibérica (Alday et al. 2009). Entre outras conclusões então apresentadas, salientam-se duas por terem implicações diretas no entendimento das realidades portuguesas:

1. É concebível que as produções de estilo boquique possam ser resultado da influência dos últimos grupos mesolíticos, uma vez que [...] debe retenerse que en buena parte su extensión es coincidente con regiones donde hay un inmediato pasado mesolítico [...]; en Portugal, aunque debe detallarse según regiones, esta máxima también se confirma (p. 148). Este é de facto o caso dos concheiros de Muge e do Sado, em cujos conjuntos cerâmicos se encontram peças decoradas com essa técnica.

2. A dispersão geográfica do cardial e do boquique mostra claramente áreas de sobreposição e áreas de "fronteira" entre ambos (Alday e Moral del Horno 2011: fig. 4.8). No entanto, [s]eñaladas algunas convivencias geográficas de ambas técnicas decorativas, parece oportuno recordar que, en principio, entre ambas modalidades no puede asegurarse una clara cisura cronológica (quizá con alguna excepción en la Extremadura Portuguesa, sobre la que debería ahondarse) [...]. Como ya hemos explicado, faltan niveles cardiales previos a los primeros contextos con boquique neolítico en las regiones donde éste se manifiesta con más fuerza. Por tanto, en ellas el cardial no es anterior (p. 151).

Com efeito, uma reapreciação crítica dos dados de terrenos e das datações de radiocarbono de vida curta disponíveis, permite precisar melhor estes aspetos da relação entre cardial e boquique (fig. 1).

Em estudos recentes sobre a arqueologia neolítica da Galeria da Cisterna da Gruta do Almonda, a componente cerâmica pôde ser ordenada num quadro tipológico próprio recorrendo, sobretudo, a critérios de comparação estilística dos 40 vasos que haviam sido individualizados (Zilhão 2009; Zilhão e Carvalho 2011). Estes foram organizados em três grupos tipológicos principais, designados por "Cardial antigo" (dois vasos), "Cardial recente" (25 vasos) e "Epicardial" (13 vasos, um dos quais decorado com boquique). Em ambos os trabalhos citados é proposto que a esta classificação tipológica corresponde um ordenamento também temporal. As datações de radiocarbono existentes sobre adornos e restos humanos (ca. 5500-5200 cal BC), assim como duas de termoluminescência sobre cerâmica de estilo epicardial (transição VI/V milénios a.C.), parecem corroborar aquele modelo (Carvalho 2018), pelo menos nos seus traços essenciais. Isto significa, em suma, que o boquique datará de um momento por enquanto indeterminado mas seguramente posterior aos conjuntos cardiais.

No que respeita aos vestígios reconhecidos na Encosta de Sant'Ana, estes são aparentemente homogéneos do ponto de vista cultural (Costa e Muralha 2006) e contam com cinco datações absolutas: duas sobre carvões de espécies indeterminadas provenientes da unidade estratigráfica UE04 (Sac-1893: 5420 土 45 BP; Sac-1894: 5140 \pm 140 BP), um depósito de coluvião; duas obtidas a partir de ácidos húmicos de um solo enterrado pré-neolítico, correspondente ao sub-horizonte $\mathrm{Ab} 2$ e contendo várias estruturas arqueológicas negativas (Sac-2004: $6880 \pm 70$ BP; Sac-2002: $7310 \pm 90$ BP); e uma datação sobre conchas de mexilhão (Mytilus edulis) retiradas de uma estrutura negativa de tipo fossa aberta no referido solo enterrado (Sac-1990: $6450 \pm 50$ BP). Se se atentar ao contexto sedimentar específico de cada amostra e à natureza da mesma, torna-se claro que somente a datação Sac-1990 se refere, de forma direta, a um evento antrópico (para o processo de formação da jazida, ver Angelucci et al.2007); os ácidos húmicos do paleossolo são-lhe anteriores e os carvões dispersos no coluvião são de origem indeterminada. Em síntese, a única atribuição cronométrica fiável para a ocupação humana é, apesar do efeito de reservatório oceânico inerente à datação de conchas marinhas, a da datação Sac-1990, a qual se centra em ca. 5000 cal BC.

Para a Valada do Mato dispõe-se também de cinco datações. Uma é sobre carvões da UE7, uma estrutura pertencente ao único nível neolítico do sítio (Beta153914: 6030 土50 BP), e quatro sobre a fração inorgânica de ossos queimados de mamíferos exumados da mesma estrutura (GrA-18298: $6530 \pm 90$ BP; GrA-18296: $6370 \pm 80$ BP; Wk-12076: $6316 \pm 37$ BP; Wk-12077: $6676 \pm 37 \mathrm{BP})$. A maior antiguidade, recorrente mas nem assim coerente entre si, dos resultados sobre as amostras de ossos e o facto de ser abundante a literatura da especialidade sobre os problemas inerentes à interpretação de 

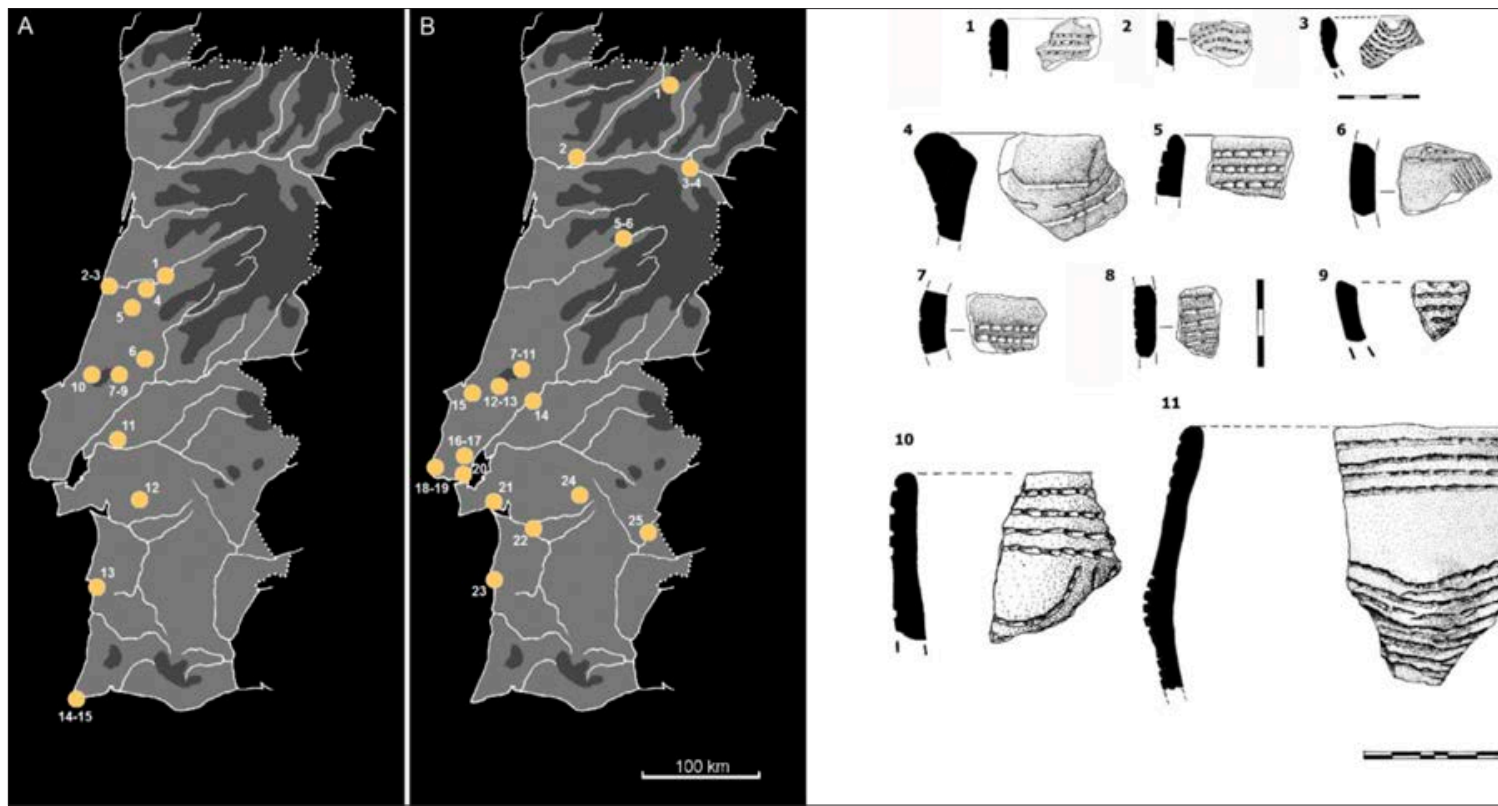

10

11

1
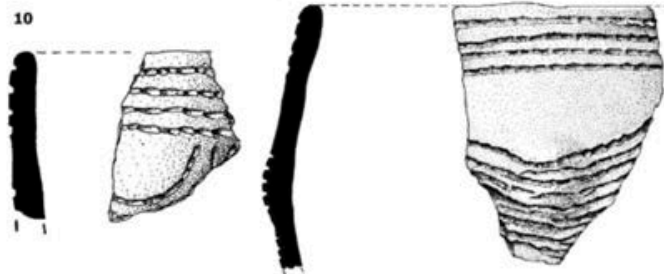

Fig. 1: Cardial e boquique no Neolítico antigo português:

Mapa A: sítios cardiais (Carvalho 2011: fig. 11.1, atualizada). 1. Senhora da Alegria (Coimbra); 2.-3. Junqueira e Várzea do Lírio (Figueira da Foz); 4. Eira Pedrinha (Condeixa); 5. Buraca Grande (Pombal); 6. Gruta do Caldeirão (Tomar); 7.-9. Abrigo da Pena d'Água, Cerradinho do Ginete e Galeria da Cisterna da Gruta do Almonda (Torres Novas); 10. Gruta III do Cabeço da Ministra (Alcobaça); 11. Casas Novas (Coruche); 12. Gruta do Escoural (Montemor-o-Novo); 13. Vale Pincel (Sines); 14. Cabranosa (Vila do Bispo); 15. Padrão (Vila do Bispo). Mapa B: sítios com boquique (Alday et al. 2009: mapa 1, atualizado). 1. Vinha da Soutilha (Vila Pouca de Aguiar); 2. Lavra (Marco de Canaveses); 3.-4. Prazo e Quinta da Torrinha (Vila Nova de Foz Côa); 5. Penedo da Penha (Nelas); 6. Buraco da Moura de São Romão (Seia); 7.-11. Gafanheira, Abrigo da Pena d'Água, Forno do Terreirinho, Laranjal de Cabeço das Pias e Galeria da Cisterna da Gruta do Almonda (Torres Novas); 12.-13. Abrigo Grande das Bocas e Cabeço de Porto Marinho (Rio Maior); 14. Cortiçóis (Almeirim); 15. Casa da Moura (Peniche); 16.-17. Pedreira de Salemas e Gruta do Correio-Mor (Loures); 18.-19. São Pedro de Canaferrim e Castelo dos Mouros (Sintra); 20. Encosta de Santana (Lisboa); 21. Casal da Cerca (Palmela); 22. Cabeço do Pez (Alcácer do Sal); 23. Samouqueira II (Sines); 24. Valada do Mato (Évora); 25. Xarês 12 (Reguengos de Monsaraz).

Exemplos de peças decoradas com boquique de sítios do Neolítico antigo do centro da Estremadura: 1.-3. Abrigo da Pena d'Água; 4.-8. Forno do Terreirinho; 6.-10. Laranjal de Cabeço das Pias; 11. Galeria da Cisterna da Gruta do Almonda (Alday et al. 2009: fig. 33, adaptada).

datações sobre este tipo de amostras, levou a responsável pelo estudo do sítio a optar, e bem, pela rejeição destas últimas: [ $p$ ] erante estes dados não se consideram as datas de radiocarbono obtidas sobre o carbono inorgânico dos ossos, e utiliza-se unicamente o resultado da amostra Beta-153914 para datar a ocupação neolítica da Valada do Mato, ou mais exatamente o momento terminal da utilização da estrutura pétrea U.E.5 [...] (Diniz 2007: 151). Deste modo, a cronologia fiável para a Valada do Mato situar-se-á em ca. 4900 cal BC.

Elementos cronostratigráficos mais expressivos encontram-se no Abrigo da Pena d'Água. Na parte basal da estratificação neolítica deste abrigo sob rocha foi possível, com efeito, reconhecer uma clara evolução estilística dos conjuntos artefactuais (da cerâmica, em particular) ao longo dos seus três níveis do Neolítico antigo (Carvalho 1998, 2008, 2016). Como se pode observar no esquema da Figura 2, não há cerâmica boquique no mais antigo nível neolítico; este tipo cerâmico surge só no nível intermédio, aí sim em coexistência e igualdade percentual em termos de número de fragmentos com o cardial, continuando depois representado no nível superior. A decoração cardial mostra o percurso inverso: predomina no nível basal, com $29 \%$ do total dos fragmentos decorados, e decresce até já não se encontrar representada na camada Ea. Das seis datações de radiocarbono obtidas para este tramo da estratigrafia, apenas uma corresponde objetivamente a ocupação humana: a obtida a partir de carvões de zambujeiro (Olea europaea) da lareira da camada Eb-topo (Wk16418: $5831 \pm 40 \mathrm{BP}$ ), uma vez que as restantes são sobre carvões, por vezes de espécies não determinadas, dispersos nos respetivos níveis sedimentares (ver discussão em Carvalho 2008, 2016). A estratigrafia da Pena d'Água conduz, assim, a duas ilações: que o boquique surge 


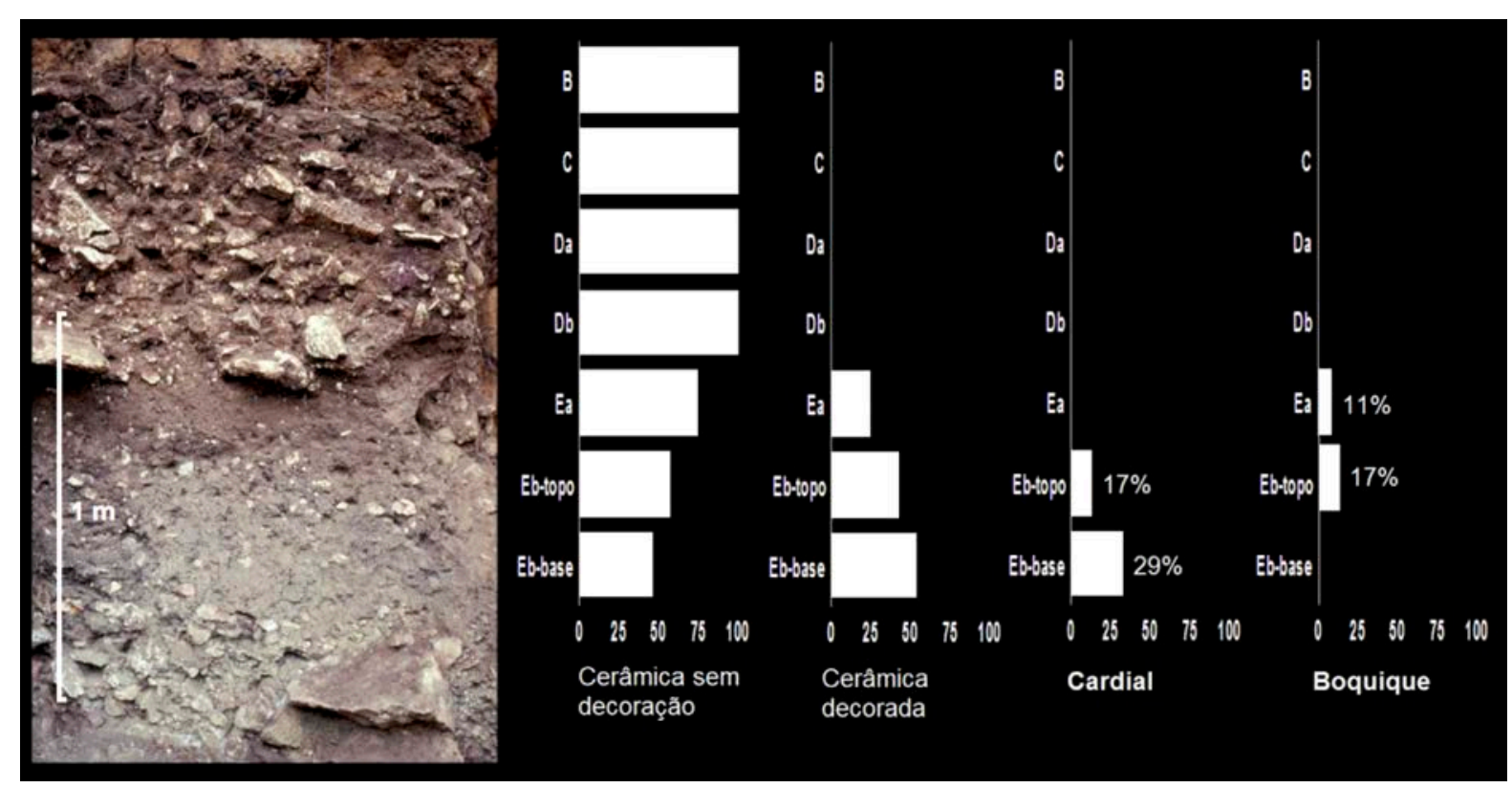

Fig. 2: Estratigrafia do Abrigo da Pena d'Água e variação vertical da relação entre cerâmica sem decoração e decorada, e entre peças cardiais e de tipo boquique.

aqui por volta de 4700 cal BC (a aceitar a datação referida), e que o seu posicionamento estratigráfico relativo indica sem margem para dúvidas que o cardial lhe é anterior. Portanto, deve prevalecer a interpretação inicial de acordo com a qual $[e]$ s interesante la presencia de decoración cardial en la fase inicial, junto a impresiones e incisiones, quedando representado el boquique desde el momento más tardío del Neolítico antiguo hasta el inicio de la fase media (Alday et al. 2009: 100), interpretação que, em suma, implica a conclusão de que coexistência de cardial e boquique no mesmo local não significa forçosamente uma exata coexistência temporal.

Por outro lado, os elementos de cronologia absoluta, obtidos nestes e noutros contextos, são coerentes em indicar o aparecimento da técnica de boquique, de forma praticamente simultânea, na Beira Alta, Estremadura e Alentejo no decorrer do primeiro quartel do $\mathrm{V}$ milénio a.C. (fig. 1); mais concretamente, no sítio do Prazo em 5100-4400 cal BC (Monteiro-Rodrigues 2011), na Quinta da Assentada em 4750 cal BC (Valera 2002/03) e no Caldeirão (Zilhão 1992) e Pena d'Água (Carvalho 1998, 2008) em $4750 / 4700$ cal BC. Outros sítios apresentam cronologias ainda mais recentes, já enquadráveis no IV milénio a.C., isto é, no Neolítico médio. Ou seja, ao contrário do entendido por Alday e Moral del Horno (2011), tanto a cronologia absoluta como as relações estratigráficas disponíveis indicam que o boquique não só não é coevo do Cardial, como claramente lhe sucede no tempo, pelo menos nas realidades portuguesas. Levando em linha de conta o quadro geral da península Ibérica apresentado por Alday et al. (2009), é mais provável, de facto, que o boquique seja uma importação proveniente das regiões mais centrais (mesetenhas) da península e que entra em cena cerca de meio milénio depois da chegada do Neolítico. A comprovar indiretamente esta conclusão estão os conjuntos cerâmicos do Neolítico antigo da gruta do Correio-Mor (Cardoso 2003) e do sítio de ar livre do Carrascal (Cardoso et al. 2008; Cardoso 2011), ambos localizados na "península de Lisboa" e datados respetivamente de $c a .5350$ e de $5250 \mathrm{cal} \mathrm{BC}$, mas que quase não apresentam boquique (apenas o último revelou um fragmento classificado como punto y raya) $)^{1}$.

A questão da coexistência espacial entre boquique e áreas de forte implantação mesolítica deve também ser entendida de forma semelhante à que se verificou acima ser a da relação com o cardial: ou seja, tratar-se-á, em todos os casos, de conjuntos associados a datações relativamente tardias. Com efeito, no que respeita ao Vale do Sado, e tanto quanto publicado até ao momento, o boquique surge apenas no Cabeço do Pez, onde se inventariaram duas peças: uma proveniente da "Sondagem E", mas desprovida de atribuição estratigráfica ou altimétrica; 


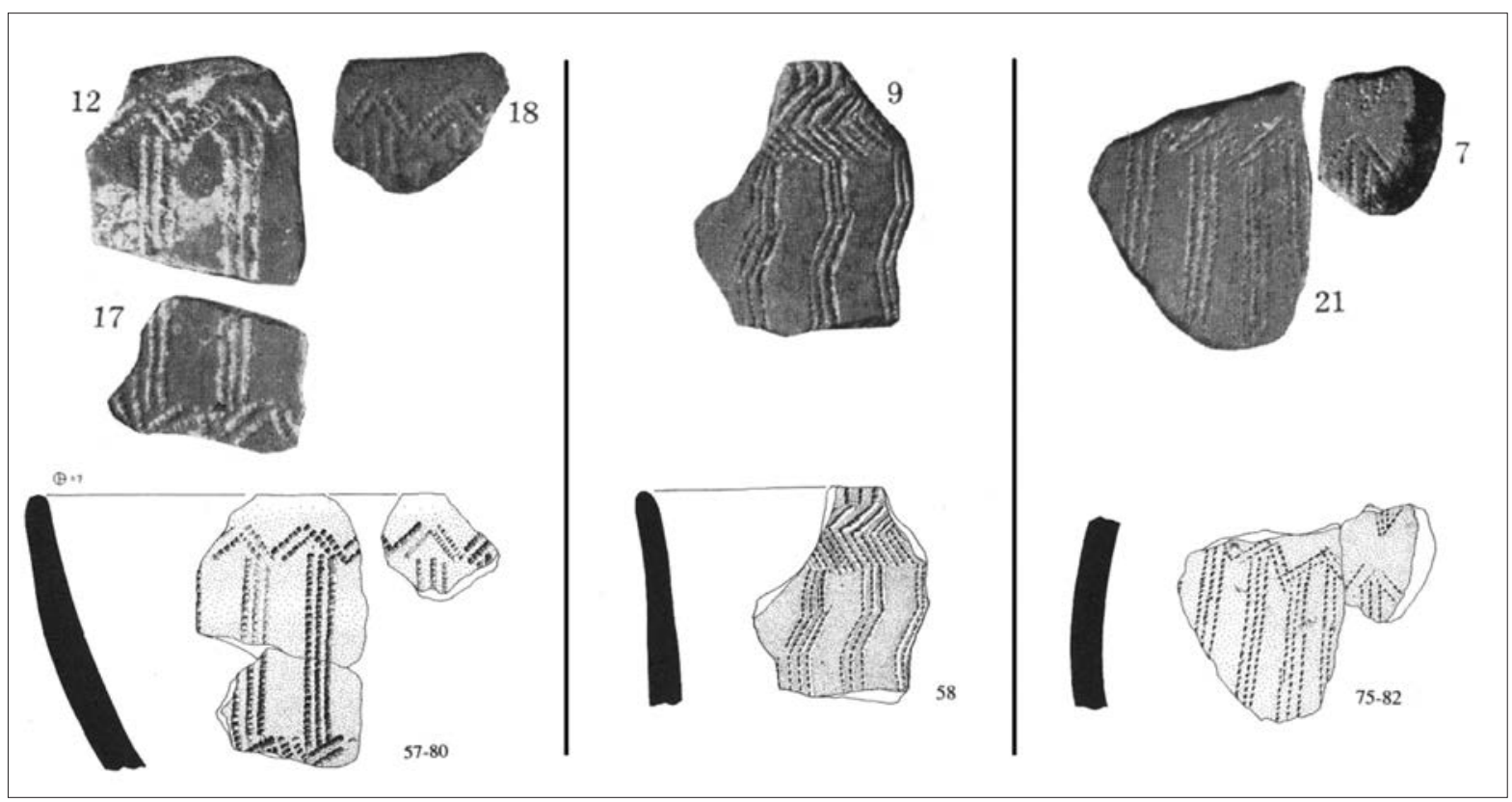

Fig. 3: Vasos cerâmicos com representações antropomórficas esquemáticas de Eira Pedrinha. Em cima: fotografias publicadas por Corrêa e Teixeira (1949: est. XI, n. ${ }^{\circ}$ 7, 9, 12, 17, 18, 21, adaptada); em baixo: desenhos correspondentes publicados por Vilaça (1988: fig. 4, n. ${ }^{\circ}$ 57-80, 58, 75-82, adaptada). Originais sem escala gráfica.

outra proveniente da "Sondagem G (0,25-0,50 m)" (Santos et al. 1974: est. I, n. ${ }^{\circ} 6$ e 18, respetivamente), portanto presumivelmente integrante dos níveis superiores deste concheiro, que contam com uma datação de ca. 4400 cal BC (Q-2499: $5535 \pm 130$ BP). Assim, a aceitar-se como fidedigna esta correspondência entre a proveniência da peça cerâmica e a amostra datada, estamos perante uma fase já muito tardia da ocupação deste concheiro (quer a classifiquemos como "neolítica", quer a classifiquemos ainda como "mesolítica", como propõe Soares 2013), a qual é até posterior à de outros sítios neolíticos (ver acima).

No caso de Muge, a primeira tentativa de interpretação dos vários fragmentos de cerâmica decorada, típica do Neolítico antigo, é devida a O.V. Ferreira (1974), que lista as peças achadas na Moita do Sebastião, Cova da Onça e Cabeço da Amoreira. Porém, de acordo com as descrições e fotografias publicadas, nenhum desses achados parece ser de atribuir a boquique. Apenas nas escavações que estão presentemente a ser levadas a cabo naquele último concheiro se recuperaram alguns fragmentos deste tipo (Bicho et al. 2010: fig. 3). Estes, porém, são provenientes de contextos remexidos sobrejacentes ao corpo de concheiro do sítio, correspondendo a [...] vários horizontes do Neolítico antigo e médio, localizados na
Área 1 e na Vala, ambos fora do limite do concheiro, $e$ estratigraficamente acima das camadas mesolíticas (Bicho et al. 2013: 64). Estes achados confirmam, assim, a interpretação do autor acima referido, segundo o qual estas cerâmicas datarão de um momento pós-mesolítico.

\section{AS PRIMEIRAS "CERÂMICAS SIMBÓLICAS" NO NEOLÍTICO PORTUGUÊS}

Foi M. Diniz (2009) quem procedeu a um primeiro inventário das (escassas) ocorrências de "cerâmica simbólica" do Neolítico antigo português e quem, talvez também pela primeira vez, tenha reconhecido como tais as notáveis representações antropomórficas presentes nalgumas peças cerâmicas de Eira Pedrinha e da Galeria da Cisterna da Gruta do Almonda. Com efeito, na referida publicação são apresentados dois vasos de cada um daqueles sítios de gruta, estilisticamente atribuíveis ao Cardial, e um fragmento de outro do sítio de ar livre da Valada do Mato, já anteriormente publicado pela mesma autora (Dinis 2007, 2011; ver abaixo), todos no entanto partilhando a figuração do mesmo tema: representações antropomórficas esquemáticas, evocativas das "figuras orantes" da arte rupestre peninsular. Trabalhos mais 
recentes, levados a cabo nos sítios de Castelo dos Mouros e Costa do Pereiro, aumentaram não só o número de peças integráveis nesta categoria como, sobretudo, alargaram o espectro de representações a temas soliformes, zoomórficos e, muito possivelmente, vegetalistas. Estes desenvolvimentos da investigação vieram assim revelar um inesperado comportamento simbólico das primeiras sociedades neolíticas do ocidente peninsular, materializado nas suas produções cerâmicas. Dentro deste panorama da "cerâmica simbólica", conquanto não se trate de um recipiente, importa também não deixar de referir um outro notável achado da Valada do Mato, uma estatueta ou figurinha antropomórfica maciça, fragmentada talvez intencionalmente, com representação de decorações corporais ou vestuário obtidas através de impressões e seu preenchimento a pasta branca (Diniz 2008: fig. 3; 2009: fig. 5; 2011: fig. 2).

Os vasos com decoração antropomórfica integram-se em ambas as fases em que se subdivide o Neolítico antigo. Todos apresentam um esquematismo evidente, mas obedecem a diferentes graus de estilização da representação humana.

O conjunto de peças cuja cronologia será mais antiga (5500-5200 cal BC) foi encontrado nos complexos cársicos de Eira Pedrinha e Galeria da Cisterna da Gruta do Almonda, e representam figuras humanas de elevado esquematismo formal. Trata-se de um total de cinco vasos. As três peças do primeiro sítio (fig. 3) não foram descritas pela primeira publicação que lhes faz referência mas apenas fotografadas em conjunto com outras, de diferentes momentos de ocupação deste conjunto de cavidades (Corrêa e Teixeira 1949: est. IX). A sua identificação como pertencendo ao mundo Cardial é feita mais tardiamente, por Guilaine e Ferreira (1970), e a sua descrição será levada a cabo por Vilaça (1988). São todas impressas e formam uma composição formada por bandas verticais unidas, no topo e na base, por bandas mais estreitas, ziguezagueantes. Os dois vasos do Almonda (fig. 4) repetem a mesma técnica observada na Eira Pedrinha (Carvalho 2008), apresentando um deles a mesma organização das bandas impressas acima descrita ("Vaso I"), e outro uma variante ainda mais esquemática formada somente, pelo menos na área conservada do mesmo, por bandas em ziguezague dispostas na vertical ("Vaso II"). Estes tipos decorativos evocam, de forma assombrosa, um dos vasos da Cova de l'Or publicado por Martí e Hernández (1988: 72 e fig. 18, n. ${ }^{\circ}$ 1), cuja descrição da composição decorativa poderia ser quase diretamente transposta para os homólogos portugueses: [...] figuras humanas con el cuerpo formado por una ancha barra vertical que se prolonga en una cabeza de tendencia triangular, unidos por sus brazos y piernas. [...] En su

Fig. 4: Vasos I e II da Galeria da Cisterna da Gruta do Almonda com representações antropomórficas esquemáticas. À esquerda: estampa publicada por Carvalho (2008: est. 37); à direita: fotografia publicada por Zilhão (2009: fig. 4). Escala $=1 \mathrm{~cm}$.

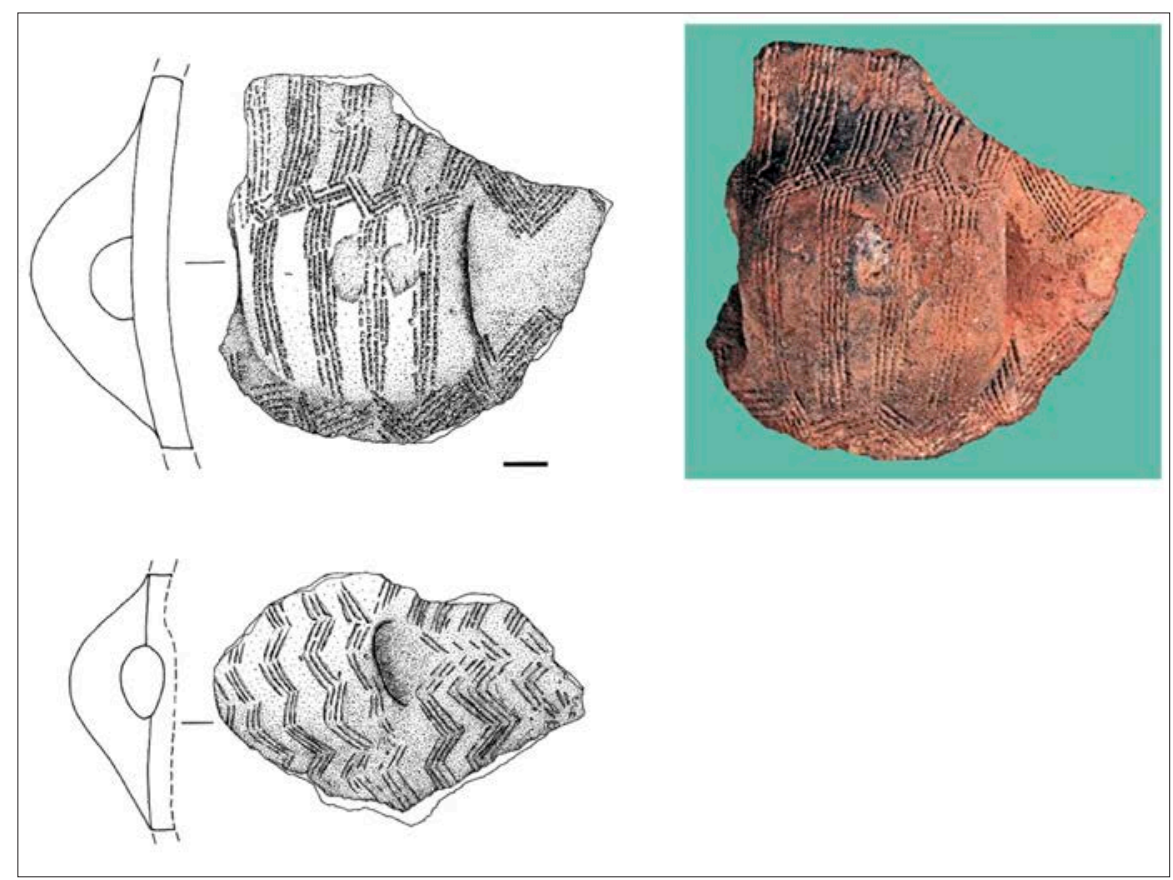




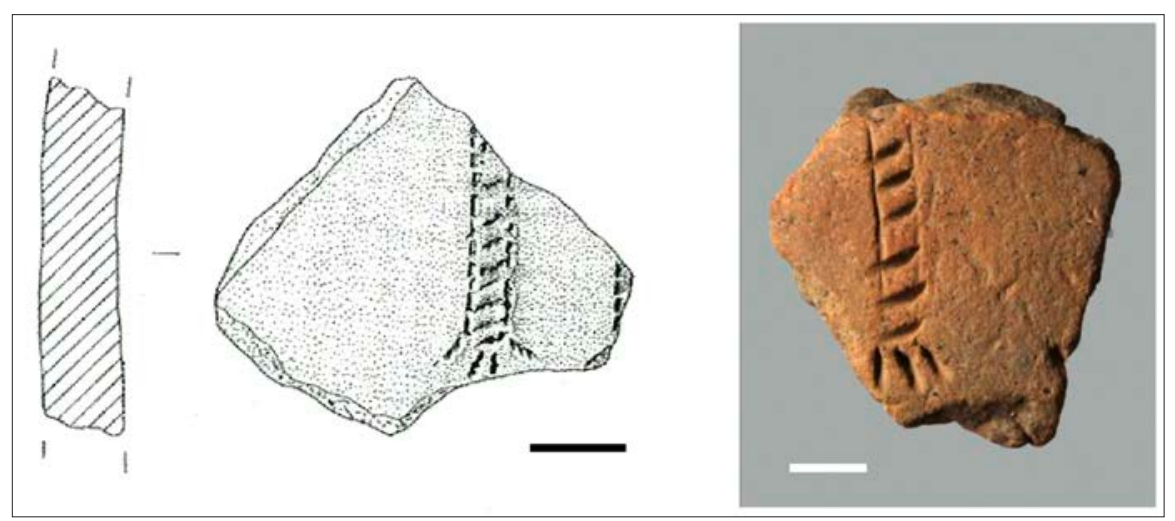

Fig. 5: Representações antropomórficas da Valada do Mato (Diniz 2007: fig. 82) e do Castelo dos Mouros (Sousa e Carvalho 2015: fig. 2; foto de Matthias Tissot, Archeofactu). Escala $=1 \mathrm{~cm}$.

conjunto estas figuras humanas parecen evocar una actividad de danza. A diferença reside apenas na técnica empregue: impressão cardial no caso valenciano, impressão com pequeno pente no caso português.

O outro conjunto de representações antropomórficas vem de contextos claramente posteriores, atribuídos à passagem do VI para o V milénio a.C., e parecem assumir um naturalismo mais notório, se se levar em linha de conta o facto de incluírem a representação de pormenores anatómicos (dedos). Como referido acima, a peça da Valada do Mato foi já objeto de publicação detalhada mas retoma-se a sua imagem aqui para efeitos comparativos com uma peça semelhante encontrada nas escavações que foram levadas a cabo recentemente no Castelo dos Mouros (fig. 5), em Sintra (Sousa e Carvalho 2015; Fernandes et al. 2016). O fragmento da Valada do Mato foi descrito como representando parte dos membros inferiores de uma figura, presumivelmente de tipo "orante", elaborada através de impressões a pente, e [...] composto por duas linhas paralelas de impressões, internamente segmentadas pela aplicação na oblíqua do mesmo pente, e de onde partem quatro "dedos". Junto a uma das áreas de fractura da peça é ainda visível a figuração de um outro "dedo", e o limite interno do outro membro inferior (Diniz 2007: 139). O fragmento do Castelo dos Mouros, por seu lado, conquanto muito semelhante formalmente (trata-se também de um membro inferior, com três dedos), foi obtido através da conjugação de linhas incisas para delimitação do motivo e seu preenchimento com impressões realizadas com recurso a um instrumento pontiagudo, de tipo punção.

O primeiro reconhecimento explícito da representação de temas zoomórficos em produções cerâmicas neolíticas, e a sua integração na fase antiga do período, deve-se a O.V. Ferreira, que classifica, muito expressivamente, alguns elementos de preensão de morfologia bífida como sendo [...] a estilização da silhueta da cabeça de um suídeo (1970: 230). Estas pegas surgem quase sempre junto ao bordo do recipiente e fazem-se muitas vezes acompanhar de bandas impressas ou incisas, dispostas na vertical ou na horizontal, no terço superior da peça. Os vasos com estes elementos encontram-se tanto em contextos funerários como habitacionais e partilham uma distribuição geográfica confinada aos baixos vales dos rios Tejo e Sado. Nestes conjuntos estão, no entanto, representadas numerosas variações morfológicas daquelas pegas - cujo ordenamento tipológico deveria ser feito no futuro - e só algumas se assemelham de forma explícita a uma cabeça de animal. A expressão "cabeça de suídeo", proposta pelo autor citado, ganhou um significado acrescido a partir dos materiais do Castelo dos Mouros, onde estas pegas estão particularmente bem representadas (fig. 6, n. ${ }^{\circ}$ 2-3), porque surgem associadas a um fragmento com a representação de metade (parte anterior?), e respetivos membros, de um quadrúpede cuja classificação taxonómica não é, contudo, possível precisar (fig. 6, n. ${ }^{\circ} 1$ ). Esta leitura da peça parte da constatação de que as incisões que representam os dedos se apresentam orientadas para a direita do observador, e não para baixo, como se verifica na representação antropomórfica do mesmo sítio. Ambos os temas foram, no entanto, conseguidos com recurso à mesma associação de técnicas.

Nos achados do Castelo dos Mouros não deixa de ser reveladora a associação entre aqueles temas antropomórficos e animalistas, por um lado, e motivos denominados "em espiga" ou "falsa folha-de-acácia", por outro. A técnica empregue na realização deste último tipo decorativo é, aliás, também primeiramente descrita por Ferreira (1970) no mesmo trabalho em que aborda as pegas em "cabeça de suídeo", no qual define a "falsa folha de 
acácia" como sendo obtida através de [...] punção manual. É, pois, uma ornamentação incisa por recorte (p. 230), diferenciando-se de uma decoração aparentada: as [...] curiosas combinações de foliáceas, em nosso entender as verdadeiras folhas de acácia, porque são conseguidas com uma matriz, ou seja, por estampilhagem ou estampagem e não a punção (p. 232). A técnica usada na "falsa folha de acácia" foi, no entanto, erradamente classificada; como muito bem refere Silva (1999: 165), [...] $a$ chamada «falsa folha de acácia» não é obtida por incisão, como pretende aquele autor, mas sim pela impressão de punção actuado obliquamente [...]. Independentemente da técnica utilizada, o importante para o estudo da simbólica da decoração cerâmica neolítica antiga é, porém, o facto de estarmos, ao que tudo indica, perante a representação esquemática de cereais, temática central para o período em estudo. No sentido desta hipótese classificativa concorre o recente reconhecimento da figuração de cereais num fragmento de cerâmica do Cabeço do Pez: de acordo com Soares (2013: 29-31 e figs. 19, 21 e 22), [a] decoração com o motivo "espiga", em geral (Estremadura e Alentejo) organizado em bandas paralelas ao bordo, possui no Cabeço do Pez uma composição original e muito dinâmica, constituída por trama de "espigas" $e$ "hastes de cereal", onde podemos ler uma alusão a seara em movimento [...].

Em síntese, e como concluído por Fernandes et al. (2016: 36-37), [e]sta associação parece fazer parte integrante de um forte discurso simbólico de afirmação dos modos de vida neolíticos, associando temas animalistas e vegetalistas que poderemos, pelo menos provisoriamente, considerar domésticos. Nesta perspetiva, estas cerâmicas simbólicas podem ser um reflexo de uma nova realidade emergente, económica e ideológica.

A "cerâmica simbólica" do Neolítico antigo português, porém, não se esgota nestas representações de seres vivos. Com efeito, no sítio de ar livre da Costa do Pereiro foi recuperado um pequeno conjunto de fragmentos com decoração cardial, ainda inéditos, sendo um deles integrável naquela categoria. Infelizmente, estas peças são intrusivas em contexto do Neolítico médio, tendo muito provavelmente derivado da vertente (não escavada) que se desenvolve acima da pequena plataforma onde tiveram lugar as escavações (Carvalho 2008). De facto, no seio daquele conjunto cardial identificou-se uma representação solar obtida pela associação de uma ligeira

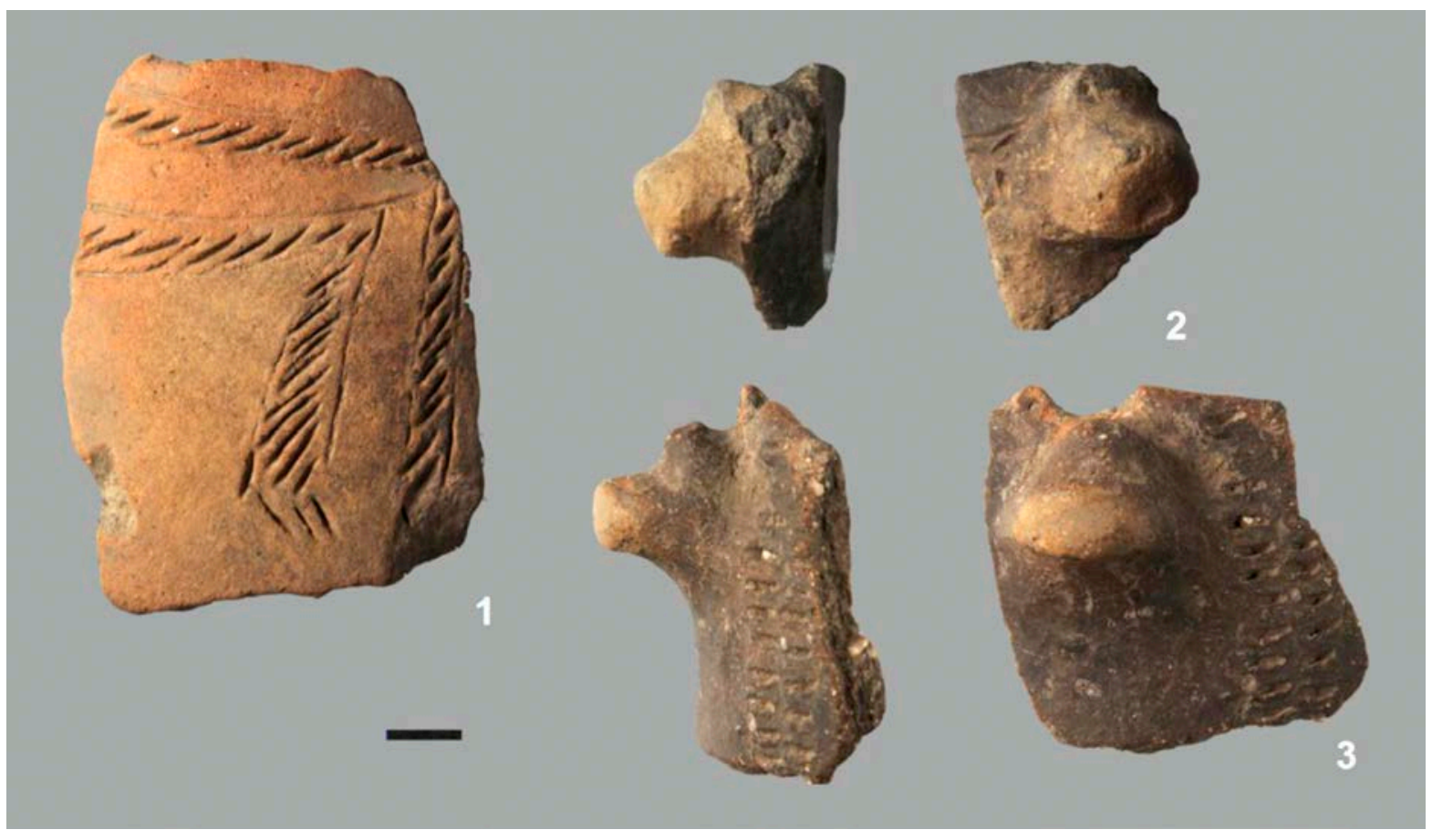

Fig. 6: Representações zoomórficas do Castelo dos Mouros (Fernandes et al. 2016: figs. 3 e 5, adaptadas; fotos de Matthias Tissot, Archeofactu). Escala $=1 \mathrm{~cm}$. 


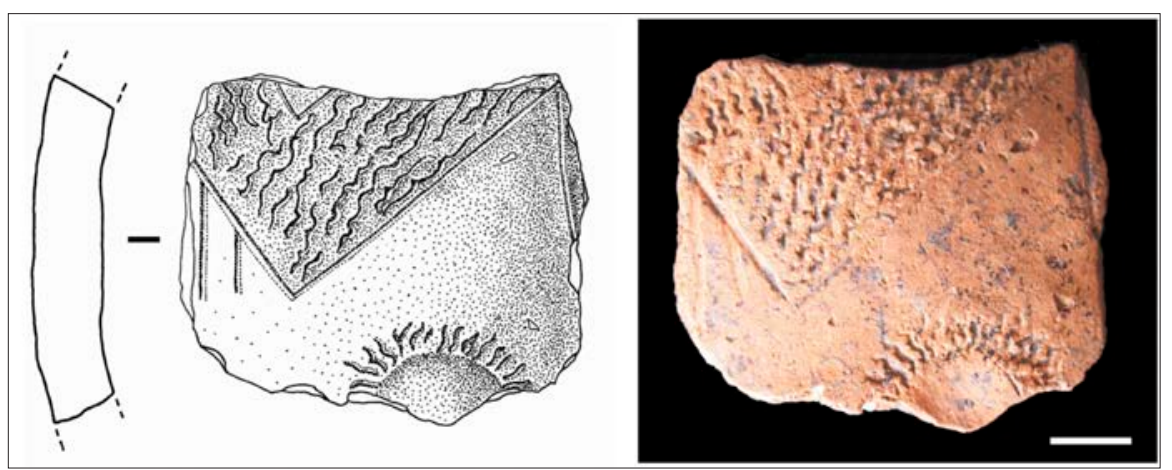

Fig. 7: Fragmento de vaso cardial da Costa do Pereiro com soliforme e vértice de barra preenchida com impressões (inédito). Escala $=1 \mathrm{~cm}$.

concavidade, de perímetro circular, bordeada por curtas impressões cardiais simulando os raios solares (fig. 7). Talvez sem relação direta com este motivo, o mesmo fragmento ostenta ainda uma banda incisa, preenchida com impressões cardiais desorganizadas, que conforma um ângulo agudo apontando para a base do recipiente (se a orientação da peça, difícil de estabelecer, estiver correta tal como representada na sua ilustração). Trata-se da única representação do género conhecida até ao momento no Neolítico antigo de Portugal e complementa, de modo muito significativo, as restantes manifestações simbólicas.

\section{CIRCULAÇÃO CERÂMICA DURANTE A NEOLI- TIZAÇÃO DO OCIDENTE PENINSULAR}

A larga maioria dos projetos de análise de petrografia e química de cerâmicas arqueológicas em Portugal tem sido consignada ao estudo de conjuntos de épocas históricas, sobretudo materiais anfóricos romanos. Para o $\mathrm{Ne}$ olítico antigo do S português, haviam sido publicados até há pouco apenas três estudos, todos de carácter petrográfico - um sobre amostras de sítios da região do Baixo Mondego (Tavares 1988), outro sobre a cerâmica neolítica da Gruta do Caldeirão (Barnett 1987, 1992) e um terceiro sobre diversos sítios da região de Rio Maior (Masucci 1995) - aos quais se somam um quarto, publicado recentemente, sobre os concheiros do Sado (Diniz e Cubas 2015). Para as regiões do centro-norte, neolitizadas num momento imediatamente subsequente, conta-se também com algumas análises de proveniência de cerâmica do Neolítico antigo (Jorge et al. 2005, 2013). No seu conjunto, aqueles três primeiros estudos pareciam apontar, entre outras conclusões, para uma tendência cuja verificação se impunha a partir de uma base de dados mais alargada e representativa: que parte das produções cardiais era manifestamente distinta, não só de algumas suas homólogas, como sobretudo de peças estilisticamente não cardiais. No sentido da verificação desta aparente tendência, foi levado a cabo um projeto de análise de amostras de diversos sítios do Neolítico antigo do Maciço Calcário Estremenho e do extremo ocidental do Algarve, para efeitos comparativos, tendo os seus principais resultados sido publicados há pouco (Masucci e Carvalho 2016). Os protocolos e opções metodológicas encontram-se descritos, e poderão ser consultados, no artigo referido; reserva-se para o presente trabalho apenas a apresentação de algumas das conclusões mais significativas.

O projeto utilizou um conjunto de 59 amostras sedimentares (33 do Maciço Calcário Estremenho, 26 do Algarve ocidental), recolhidas num raio de $7 \mathrm{~km}$ em torno dos 14 sítios em estudo (oito estremenhos e seis algarvios), os quais, por seu lado, forneceram um total de 63 amostras cerâmicas (48 da primeira região, 15 da segunda). Neste universo foi possível identificar sete grupos de argilas e cinco classes de fabricos cerâmicos. De um ponto de vista geral, os grupos de argilas e as classes de fabrico são mutuamente exclusivas de uma ou outra região, o que significa que a larga maioria dos espécimes cerâmicos estudados são produções locais. Porém, há um pequeno conjunto de oito amostras de cerâmica (ou seja, ca. 13\% do total) que se constituem como exceções a esta regra, pois não foi possível a sua inclusão em qualquer grupo de argila ou classe de fabrico reconhecidos como sendo caracteristicamente da região onde se localizam os respetivos sítios arqueológicos. Trata-se, no caso do Maciço Calcário Estremenho, de três peças cardiais provenientes do Abrigo Grande das Bocas, Cabeço de Porto Marinho e Galeria da Cisterna da Gruta do Almonda e, no caso do ocidente algarvio, de cinco peças: dois exemplares lisos 

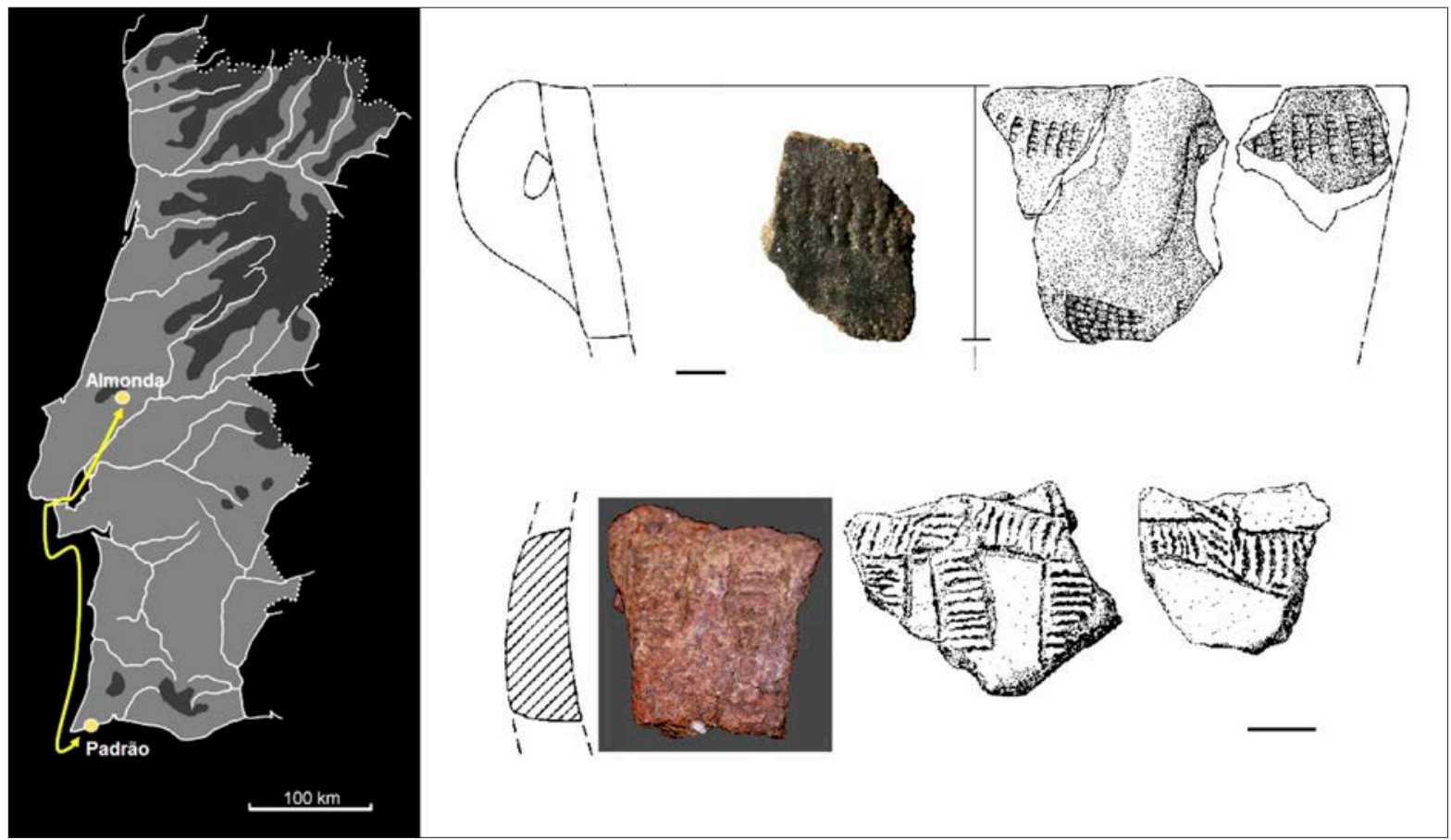

Fig. 8: Circulação de cerâmica cardial no VI milénio a.C., entre o Algarve ocidental (Vaso 1 do Padrão; Carvalho 2008: est. 73, n. ${ }^{\circ}$ 1, adaptada) e a Estremadura Portuguesa (Vaso XXI da Galeria da Cisterna da Gruta do Almonda; Carvalho 2008: est. 39, n. ${ }^{\circ}$ 2, adaptada). Escalas $=1 \mathrm{~cm}$.

do concheiro da Ribeira de Alcantarilha (que, aliás, são distintos entre si), um fragmento cardial do Padrão, e dois fragmentos com cordões segmentados do mesmo sítio e da Cabranosa.

A impossibilidade de atribuição das peças lisas da Ribeira de Alcantarilha a qualquer grupo de argila pode derivar de uma limitação do próprio projeto: o facto de a amostragem de sedimentos da envolvência ter sido muito limitada, podendo dessa forma não representar adequadamente as variações geológicas locais. Independentemente destas peças lisas, retiram-se deste estudo duas grandes conclusões: em primeiro lugar, as peças consideradas como não locais são recorrentemente de tipo cardial, tal como já reconhecido nos estudos anteriores; em segundo lugar, observou-se que as peças com cordões plásticos se constituem também por vezes como não locais. Dito de outro modo, parece poder concluir-se que os vasos que circulam durante o Neolítico antigo são principalmente (se não exclusivamente) os decorados com cordões plásticos ou impressões cardiais. Assim sendo, é de notar que os tipos decorativos assinalados conformam apenas uma parte selecionada da variabilidade estilística que havia sido tentativamente definida para as produções cerâmicas do VI milénio a.C. em território português, entre as quais, além do cardial, [o]utros três tipos decorativos são também relevantes: as caneluras largas e pouco profundas [...], as impressões a pente imitando o cardial, e os cordões plásticos lisos ou segmentados por impressões ou incisões (Carvalho 2011: 248). A amostragem utilizada neste projeto parece também sugerir que a referida circulação de vasos cerâmicos tem uma expressão mais significativa no VI milénio a.C., parecendo reduzir-se (ou extinguir-se totalmente) no milénio seguinte.

Só o prosseguimento da investigação poderá confirmar em definitivo as conclusões acima aventadas. Porém, um dado muito interessante - e mesmo inesperado - se pode desde já considerar adquirido: o transporte a longa distância de cerâmica cardial. Com efeito, duas das peças acima apontadas como não tendo correspondência com os grupos de argila nem com as classes de fabrico das respetivas regiões apresentam-se, no entanto, coincidentes com resultados obtidos na região oposta. Trata-se de uma peça cardial da Galeria da Cisterna da Gruta do Almonda - pertencente ao "Vaso XXI" (Carvalho 2008; cf. Zilhão 2009) - e outra peça cardial do sítio de Padrão - pertencente ao "Vaso 1" (Carvalho 2008; cf. Gomes 
1997) - cujas características petrográficas e químicas são apresentadas e discutidas por Masucci e Carvalho (2016). Conquanto não se deva excluir liminarmente a possibilidade de terem sido transportadas por via terrestre ao longo dos $350 \mathrm{~km}$ que separam em linha reta as duas regiões, parece no entanto mais razoável, considerando a fragilidade destes objetos, colocar a hipótese alternativa do transporte por via marítima ao longo da costa SO e através do interior da ria flandriana do Tejo (fig. 8). Este dado concreto vem, assim, atestar indiretamente não só a verosimilhança da colonização marítima como modelo explicativo para o surgimento do Neolítico nas regiões consideradas, como também indicar de forma clara a existência de circulação de cerâmica nos dois sentidos, e não apenas sul-norte como implícito naquele modelo.

\section{CONSIDERAÇÕES FINAIS}

Pese embora alguns desenvolvimentos relevantes que têm tido lugar nos últimos anos no respeitante ao estudo das produções cerâmicas do Neolítico antigo, a que se fez referência nas páginas precedentes, há ainda um conjunto de lacunas por colmatar. Para além das que se foram apontando anteriormente, é de ressaltar a inexistência de estudos de escala regional sobre variabilidade estilística e formal, suportados por um criterioso enquadramento cronostratigráfico dos conjuntos que permita desenhar fronteiras estilísticas, transformações na diacronia e influências inter-regionais. Tanto quanto o prosseguimento dos projetos de caracterização e proveniência de matérias-primas, ou a introdução de análises de resíduos, esse trabalho elementar de sistematização do corpus cerâmico providenciaria informação inestimável sobre os processos mais gerais de expansão e interação que tiveram lugar, não só no decurso do processo de neolitização das diversas regiões do atual território português, como também no âmbito geográfico mais amplo do S peninsular e do $\mathrm{N}$ marroquino (Carvalho 2018).

\section{NOTA}

1. Durante o período de submissão e revisão do presente trabalho, foram publicados em detalhe dois sítios do Neolítico antigo da região do Baixo Tejo, os Armazéns Sommer (Lisboa) e Casas Novas (Coruche), que revelaram cerâmicas de tipo boquique, associadas a cardial no segundo caso. No primeiro sítio trata-se de uma fossa de inumação individual que continha um vaso de colo com decoração de tipo boquique, organizada em grinaldas. A datação de radiocarbono obtida sobre uma amostra óssea do próprio enterramento abarca a transição VI-V milénios a.C. (Cardoso et al. 2018), o que confirma as conclusões apresentadas quanto à cronologia do aparecimento deste tipo de cerâmica no atual território português. O segundo sítio é muito singular no sentido em que, para além de uma datação de radiocarbono cuja mediana se situa em ca. 5600 cal BC (sobre carvões de espécie indeterminada depositados numa fossa da Sondagem 6), portanto ligeiramente anterior ao mais antigo Neolítico da região, exibe tipos cerâmicos diversificados que incluem cardial e boquique e, em particular, um fragmento "híbrido" (identificado na Sondagem 2, com o código V.15-91) que se encontra decorado com uma fiada de impressões cardiais junto ao bordo e um campo decorativo triangular obtido por boquique imediatamente abaixo daquela (Gonçalves e Sousa 2018). O entendimento que se pode fazer de Casas Novas é que representará um espaço de episódios sucessivos de frequentação neolítica junto a este troço do Rio Sorraia, processo que, iniciando-se na segunda metade do VI milénio a.C. com cerâmica cardial (entre outros tipos), terá atingido uma fase posterior, não datada mas já de inícios do milénio seguinte, em que este tipo decorativo e o boquique terão coexistido nos mesmos contextos e, muito paradigmaticamente, no mesmo recipiente.

\section{AGRADECIMENTOS}

Agradece-se a Raquel Vilaça (Universidade de Coimbra) e Mariana Diniz (Universidade de Lisboa) a autorização de utilização das imagens constantes, respetivamente, das figuras 3 e 5 deste trabalho, e a dois revisores anónimos pela apreciação construtiva que fizeram da versão inicial deste texto.

\section{BIBLIOGRAFIA}

ALDAY,A.; CARVALHO, A. F.; CERRILLO, E.; GONZÁLEZ,A.; JUEZ, L.; MORAL DEL HORNO, S.; ORTEGA, A. I. (2009): Reflejos del Neolítico ibérico. La cerámica boquique: caracteres, cronología y contexto, Milan.

ALDAY, A.; MORAL DEL HORNO, S. (2011): El dominio de la cerámica boquique: discusiones técnicas y cronoculturales, Las primeras producciones cerámicas: el VI milenio cal AC en la Península Ibérica (J. Bernabeu, M.Á. Rojo, Ll. Molina, coords.), València, 65-82.

ANGELUCCI, D. E.; SOARES, A. M.; ALMEIDA, L.; BRITO, R.; LEITÃO, V. (2007): Neolithic occupation and mid-Holocene soil formation at Encosta de Sant'Ana (Lisbon, Portugal): a geoarchaeological approach, Journal of Archaeological Science 34, 1641-1648. DOI: https://doi.org/10.1016/j.jas.2006.12.002 
BARNETT, W. K. (1987): The Early Neolithic impressed pottery from the Gruta do Caldeirão (Tomar, Portugal), O Arqueólogo Português 5, 67-87.

BARNETT, W. K. (1992): The physical analysis of Early Neolithic impressed pottery from Gruta do Caldeirão, Gruta do Caldeirão. O Neolítico antigo (J. Zilhão, ed.), Lisboa, 297-312.

BICHO, N. F.; PEREIRA, T.; CASCALHEIRA, J.; MARREIROS, J.; PEREIRA, V.; JESUS, L.; GONÇALVES, C. (2010): Cabeço da Amoreira, Muge: resultados dos trabalhos de 2008 e 2009, Os últimos caçadores-recolectores e as primeiras comunidades produtoras do sul da Península Ibérica e do norte de Marrocos (J. F. Gibaja, A. F. Carvalho, eds.), Faro, 11-22.

BICHO, N. F.; PEREIRA, T.; GONÇALVES, C.; CASCALHEIRA, J.; MARREIROS, J.; DIAS, R. (2013): Os últimos caçadores-recolectores do Vale do Tejo: novas perspectivas sobre os concheiros de Muge, Pré-História das zonas húmidas. Paisagens de sal (J. Soares, ed.), Setúbal, 57-68.

CARDOSO, J. L. (2003): A gruta do Correio-Mor (Loures), Estudos Arqueológicos de Oeiras 11, 229-322.

CARDOSO, J. L. (2011): A estação do Neolítico antigo do Carrascal (Oeiras, Lisboa, Portugal), Las primeras producciones cerámicas: el VI milenio cal AC en la Península Ibérica (J. Bernabeu, M. Á. Rojo, L1. Molina, coords.), València, 259-262.

CARDOSO, J. L.; REBELO, P.; NETO, N.; RIBEIRO, R. Á. (2018): Enterramento do Neolítico Antigo em fossa na zona ribeirinha de Lisboa (antigos Armazéns Sommer), Volume comemorativo do XXX aniversário do Centro de Estudos Arqueológicos do Concelho de Oeiras, 19882018 (J. L. Cardoso, coord.). Oeiras, 125-140.

CARDOSO, J. L.; SILVA, C. T.; SOARES, J. (2008): A ocupação do Neolítico antigo do povoado do Carrascal (Leceia, Oeiras), Octávio da Veiga Ferreira. Homenagem ao Homem, ao Arqueólogo e ao Professor (J. L. Cardoso, coord.), Oeiras, 247-267.

CARVAlHO, A. F. (1998): Abrigo da Pena d’Água (Rexaldia, Torres Novas): resultados das campanhas de sondagem (1992-1997), Revista Portuguesa de Arqueologia 1(2), 39-72.

CARVAlHO, A. F. (2008): A neolitização do Portugal meridional. Os exemplos do Maciço Calcário Estremenho e do Algarve ocidental, Faro.

CARVALHO, A. F. (2011): Produção cerâmica no início do Neolítico de Portugal, Las primeras producciones cerámicas: el VI milenio cal AC en la Península Ibérica (J. Bernabeu, M.Á. Rojo, L1. Molina, coords.), València, 237-250.

CARVALHO, A. F. (2016): The Pena d'Água Rock-shelter (Torres Novas, Portugal): two distinct life ways within a Neolithic sequence, Del Neolític a l'Edad del Bronze en el Mediterrani occidental. Estudis en homenatge a Bernat Martí Oliver, València, 211-223.
CARVALHO,A. F. (2018): When the Mediterranean met the Atlantic. A socio-economic view on Early Neolithic communities in central-southern Portugal, Quaternary International 470, 472-484.

DOI: https://doi.org/10.1016/j.quaint.2016.12.045.

CORRÊA, A. M.; TEIXEIRA, C. (1949): A jazida pré-histórica de Eira Pedrinha (Condeixa), Lisboa.

DAVIS, S. J. M.; SIMÕES, T. (2016): The velocity of Ovis in prehistoric times: the sheep bones from Early Neolithic Lameiras, Sintra, Portugal, O Neolítico em Portugal antes do Horizonte 2020: perspetivas em debate (M. Diniz, C. Neves, A. Martins, eds.), Lisboa, 51-66.

DINIZ, M. (2007): O sítio da Valada do Mato (Évora): aspectos da neolitização no Interior / Sul de Portugal, Lisboa.

DINIZ, M. (2008): Far from Eden? Acerca de uma figurinha antropomórfica do povoado do Neolítico antigo da Valada do Mato (Évora, Portugal), Sagvntvm-PLAV 40, 9-23.

DINIZ, M. (2009): Ainda antes do $4 .^{\circ}$ milénio a.C.: as práticas simbólicas das comunidades neolíticas, no Ocidente peninsular, Volume comemorativo do XX aniversário do Centro de Estudos Arqueológicos do Concelho de Oeiras, 1988-2008 (J. L. Cardoso, ed.), Oeiras, 157-174.

DINIZ, M. (2010): O concheiro mesolítico do Cabeço das Amoreiras (S. Romão do Sado, Alcácer do Sal): um (outro) paradigma perdido? Os últimos caçadores-recolectores e as primeiras comunidades produtoras do sul da Península Ibérica e do norte de Marrocos (J. F. Gibaja, A. F. Carvalho, eds.), Faro, 49-62.

DINIZ, M. (2011): O povoado da Valada do Mato (Évora, Portugal), Las primeras producciones cerámicas: el VI milenio cal AC en la Península Ibérica (J. Bernabeu, M.Á. Rojo, Ll. Molina, coords.), València, 255-258.

DINIZ, M.; CUBAS, M. (2015): Pots for thought: Neolithic pottery in Sado Mesolithic shell middens, Muge 150th. The 150th anniversary of the discovery of Mesolithic Shellmiddens, vol. 1 (N. F. Bicho, C. Detry, T. D. Price, E. Cunha, eds.), Cambridge, 375-390.

FERREIRA, O. V. (1970): Acerca dos vasos globulares com asas perfuradas e ornamentação em "falsa folha de acácia", Actas das I Jornadas Arqueológicas, vol. II, Lisboa, 227-238.

FERREIRA, O. V. (1976): Acerca das cerâmicas neolíticas encontradas na parte superior dos concheiros da região de Muge (Portugal), Comunicações dos Serviços Geológicos de Portugal 58, 191-196.

FERNANDES, A. R.; SOUSA, M. J.; CARVALHO, A. F. (2016): "Cerâmica simbólica" neolítica do Castelo dos Mouros, Revista Portuguesa de Arqueologia 19, 33-40.

GONÇALVES, V. S.; SOUSA, A. C. (2014): Coruche e as antigas sociedades camponesas, Coruche, o céu, a terra e os homens, Coruche, 29-67.

GONÇALVES, V. S.; SOUSA, A. C. (2018): Casas Novas, numa curva do Sorraia (no 6. milénio a.n.e. e a seguir), Lisboa. 
GONÇALVES, V. S.; SOUSA, A. C.; MARCHAND, G. (2013): Na margem do grande rio. Os últimos grupos de caçadores-recolectores e as primeiras sociedades camponesas no Guadiana Médio, Beja.

GOMES, M. V. (1997): Megalitismo do Barlavento Algarvio. Breve síntese, I Encontro de Arqueologia da Costa Sudoeste. Homenagem a Georges Zbyszewski, Setúbal, 147-190.

GUILAINE, J.; FERREIRA, O. V. (1970): Le Néolithique ancien au Portugal, Bulletin de la Société Préhistorique Française 67(1), 304322.

DOI: https://doi.org/10.3406/bspf.1970.4199

JORGE, A.; DAY, P. M.; VALERA, A. C.; DIAS, M .I.; PRUDÊNCIO, M. I. (2005): Ceramics, style and exchange in the Early Neolithic Upper Mondego Basin a technological approach, Understanding people through their pottery. Proceedings of the 7th European Meeting on Ancient Ceramics (EMAC '03) (M. I. Prudêncio, M. I. Dias, J. C. Waerenborgh, eds.), Lisboa, 121-128.

JORGE, A.; DIAS, M. I.; DAY, P. M. (2013): Plain pottery and social landscapes: reinterpreting the significance of ceramic provenance in the Neolithic, Archaeometry 55 (5), 825-851.

MARTÍ, B.; HERNÁNDEZ, M. (1988): El Neolític Valencià. Art rupestre i cultura material, Valencia.

MASUCCI, M. A. (1995): Early Neolithic pottery production in the Rio Maior valley, Portuguese Estremadura, The ceramics cultural heritage. 8th CIMTEC: World ceramics congress and forum on new materials (P. Vincenzini, ed.), Faenza, 493-503.

MASUCCI, M. A.; CARVALHO, A. F. (2016): Ceramic technology and resource use during the Early Neolithic in CentralSouthern Portugal, Archaeometry 58(2), 203-215. DOI: https://doi.org/10.1111/arcm.12206

MONTEIRO-RODRIGUES, S. (2011): Pensar o Neolítico antigo. Contributo para o estudo do Norte de Portugal entre o VII e o V milénio a.C., Viseu.

MURALHA, J.; COSTA, C. (2006): A ocupação neolítica da Encosta de Sant'Ana (Martim Moniz, Lisboa), IV Congresso de Arqueologia Peninsular. Do Epipaleolítico ao Calcolítico na Península Ibérica, Faro, 157-169.
SANTOS, M. F.; SOARES, J.; SILVA, C. T. (1974): O concheiro epipaleolítico do Cabeço do Pez (Vale do Sado, Torrão). Primeira notícia, III Congresso Nacional de Arqueologia, vol. I, Porto, 173-190.

SILVA, C. T. (1999): Os Serviços Geológicos e o estudo do Neolítico antigo em Portugal, Al-Madan 8, 161-168.

SILVA, C. T.; SOARES, J. (2015): Neolitização da costa sudoeste portuguesa. A cronologia de Vale Pincel I, 5. ${ }^{\circ}$ Congresso do Neolítico Peninsular, Lisboa, 645-660.

SOARES, J. (2013): Caçadores-recolectores semi-sedentários do Mesolítico do paleoestuário do Sado (Portugal), Pré-História das zonas húmidas. Paisagens de sal (J. Soares, ed.), Setúbal, 13-56.

SOUSA, M. J.; CARVALHO, A. F. (2015): Campo de Investigação Arqueológica do Castelo dos Mouros, Sintra (Portugal): achado de um vaso neolítico inteiro, $5 .^{\circ}$ Congresso do $\mathrm{Ne}$ olítico Peninsular, Lisboa, 180-183.

TAVARES, A. (1988): Estudo petrográfico de algumas cerâmicas de jazidas neolíticas do Baixo Mondego, Subsídios para o estudo da Pré-História recente do Baixo Mondego (R. Vilaça, ed.), Lisboa, 66-73.

VALERA, A. C. (2002/03): Problemas da neolitização na bacia interior do Mondego a propósito de um novo contexto: a Quinta da Assentada, Fornos de Algodres, Estudos Pré-Históricos 10-11, 5-29.

VALERA, A. C. (2013): Cronologia dos recintos de fossos da Pré-História recente em território português, Arqueologia em Portugal: 150 anos (J. M. Arnaud, C. Neves, A. Martins, eds.), Lisboa, 335-343.

VILAÇA, R. (1988): Subsídios para o estudo da Pré-História recente do Baixo Mondego, Lisboa.

ZILHÃO, J. (1992): Gruta do Caldeirão. O Neolítico antigo, Lisboa.

ZILHÃO, J. (2009): The Early Neolithic artifact assemblage from the Galeria da Cisterna (Almonda karstic system, Torres Novas, Portugal), De Méditerranée et d'ailleurs... Hommages à Jean Guilaine, Toulouse, 821-835.

ZILHÃO, J.; CARVALHO, A. F. (2011): Galeria da Cisterna (Rede Cárstica da Nascente do Almonda), Las primeras producciones cerámicas: el VI milenio cal AC en la Península Ibérica (J. Bernabeu, M. Á. Rojo, L1. Molina, coords.), València, 251-254. 